\title{
Assessment of mechanical exposure in ergonomic epidemiology
}

\author{
Allard J van der Beek, Monique H W Frings-Dresen
}

\begin{abstract}
In recent years several different methods have been developed to assess mechanical exposures, which are related to musculoskeletal disorders in ergonomic epidemiology. Each of these methods is capable of measuring one or more aspects of risk factors, but has drawbacks as well. Improper application of methods might result in biased exposure estimates, which has serious consequences for risk estimates arising from epidemiological studies. The aim of this paper was to systematically evaluate the usefulness of different measurement methods in terms of accuracy and applicability. Assessment of external exposure measures by subjective judgements (from experts or self reports from workers), observational methods (on site or afterwards from video recordings), and direct measurements methods (at work or during laboratory simulations) are discussed for each of the dimensions of exposure level, duration, and frequency. It is concluded that expert judgements and self reports give only limited insight into the occurrence of tasks and activities. Further information can be obtained from observations, which can best be combined with direct measurements of exposure to posture, movement, and exerted forces to achieve exposure profiles by occupational task. Internal exposures estimated by biomechanical modelling mostly consider the low back and require information on postures of the different body segments and exerted forces, completed with movement data in the case of dynamic models. Moreover, electromyography (EMG) and measurements of intra-abdominal pressure might be used for this purpose. Both biomechanical models and EMG are useful methods to assess internal exposure, but biomechanical models should not be restricted to the level of compressive forces on the lower back. Finally, current problems and future directions in measurement strategies and methods are discussed.

(Occup Environ Med 1998;55:291-299)
\end{abstract}

Keywords: mechanical exposure; ergonomic epidemiology; musculoskeletal disorders
Musculoskeletal disorders are a major problem for workers and for society. In particular low back pain is experienced by a large proportion of the population in western countries as the lifetime prevalence exceeds $70 \% .^{1}$ The annual incidence of low back pain is reported to be about $5 \%$, whereas yearly prevalence varies from $15 \%-20 \%$ in the United States up to $25 \%-40 \%$ in the European countries. This has not only emotional, but also financial consequences. The total costs of back pain to society in The Netherlands has been estimated at $1.7 \%$ of the gross national product in $1991 .{ }^{1}$ In ergonomic epidemiology the relation between occupational exposure and adverse musculoskeletal health effects is studied. It has been shown that several occupational factors are related to low back disorders ${ }^{2}$ and to musculoskeletal complaints of the neck and limbs. ${ }^{3}$ By contrast with many occupational diseases that have their origin in exposure to particular hazardous agents, most musculoskeletal disorders are characterised as multifactorial. Physical, psychosocial, and individual factors contribute to the development and aggravation of musculoskeletal disorders. Although the importance of social and organisational factors at work, and individual characteristics should not be underestimated, ${ }^{4}$ in the present paper only methods to assess work related physical exposures are discussed. In epidemiological studies three scientific disciplines can be involved in the assessment of physical exposure measures - that is, occupational biomechanics, work physiology, and psychophysics. The main focus is on the assessment of biomechanical exposure, but the other two disciplines are not neglected. This paper supplements other papers on the same topic ${ }^{5-8}$ by critically describing methodological considerations and difficulties when quantifying mechanical exposures. The aim is to systematically evaluate the usefulness of the different methods in epidemiological studies, so that the paper can serve as general guidance when assessment of mechanical exposure is planned. Furthermore, starting from the systematic overview future research needs in ergonomic epidemiology are discussed.

A general model (figure) based on Van Dijk et $a l^{9}$ and Westgaard and Winkel ${ }^{10}$ that describes how the working situation evokes responses and health effects in the human 


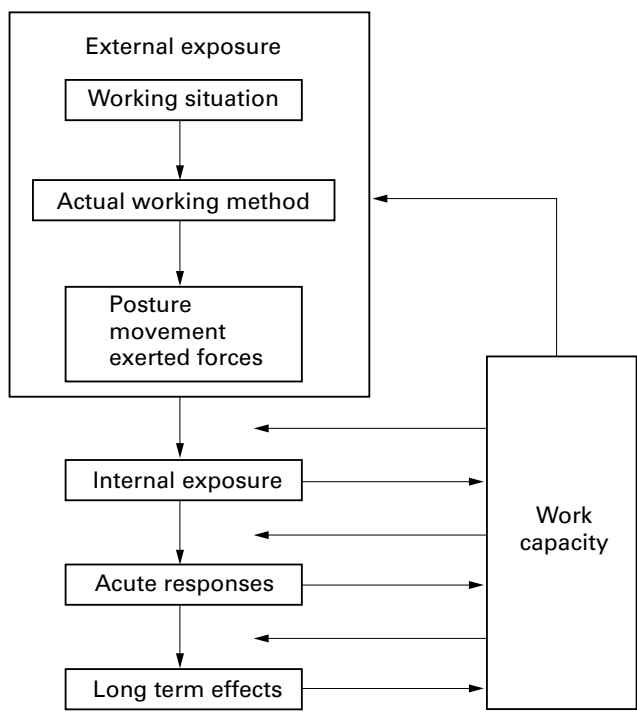

Conceptual model based on the workload, from Van Dijk et al ${ }^{9}$ and the model proposed by Westgaard and Winkel. ${ }^{10}$

organism is used as a conceptual framework in this paper (figure, and Hoozemans et $a l^{11}$ ). The working situation is characterised by work demands and decision latitude. Decision latitude is the extent of autonomy and opportunities for the worker to improve (or to worsen) the working situation by altering the work demands. This leads to an actual working method: the worker with his or her anthropometrical characteristics performs a certain activity in a certain environment. The working method compels the worker to adopt postures, execute movements, and exert forces on the environment. The working situation, the actual working method, as well as the triad postures, movements, and exerted forces are considered as external exposure. Internal exposure refers to the corresponding moments and forces within the human body. Passive structures of the musculoskeletal system are exposed to internal forces along and moments around each of the three principal axes. With respect to active structures, recruitment patterns of muscles are generated to counterbalance net moments on motion segments caused by gravity, other external forces, and inertial forces. The concept of dose is often used as synonym for internal exposure, but after Checkoway et $a l{ }^{12}$ Winkel and Mathiassen ${ }^{6}$ stated that dose comprises internal exposure during a specific time interval (the product of internal exposure level and duration). Taking into account the influence of the physical, cognitive, and emotional characteristics of the worker (his or her work capacity), internal exposure results in short term effects (acute responses in the worker) at system, tissue, cellular, and molecular level. For instance, muscle activity causes increased circulation, local muscle fatigue, and various physiological responses that include both electrochemical and metabolic changes. These short term effects represent the workload during work and some hours thereafter. In the case of insufficient recovery short term effects may expand to more permanent effects. Examples are degenerative changes in a motion segment, musculoskeletal complaints, or chronic fatigue. Most of the time these negative effects are accompanied by a decreased capacity of the worker. On the other hand, effects such as improvement of skills or physical condition lead to positive changes in the worker's capacity.

Winkel and Mathiassen ${ }^{6}$ have correctly emphasised that mechanical exposure should be expressed by all its three principal dimensions, level, duration, and frequency. Therefore, in this paper different methods to obtain information on level, duration, and frequency of mechanical exposure of the musculoskeletal system are discussed with respect to their usefulness in epidemiological studies. The fundamental division of mechanical exposure into three main dimensions holds for external exposure as well as internal exposure. However, for internal exposure attention primarily focuses on its level as its duration and frequency have hardly been explored in the scientific literature.

\section{External exposure of the musculoskeletal system}

In general, external exposure measures can be obtained by estimations on the basis of (1) subjective judgements, (2) systematic observations, and (3) direct measurements. These three methods of exposure assessment are generally in order of increasing precision. ${ }^{6}{ }^{13} \mathrm{In}$ particular for the level of exposure to postures, movements, and exerted forces the direct methods of measurement yield higher precision than other methods, as data from systematic observations and subjective judgements are crude and mostly do not get beyond interval and ordinal scale, respectively. In terms of cost and effort, however, exposures are most easily obtained by subjective judgements. Observing workers is time consuming, but direct measurements are often accompanied by high expenditure on equipment and on time for calibration and analysis.

For each of these three primary methods there are two alternatives, which give the following six methods of exposure assessment: (1a) self reports, (1b) expert judgements, $(2 a)$ observations at the workplace, $(2 b)$ video observations, ( $3 a)$ direct measurements at the workplace, and ( $3 b)$ measurements during simulations in the laboratory. Self reports of workers are obtained by means of a questionnaire, a diary, or an interview. Methods that make use of expert judgements include, among others, assessments on the basis of job title and checklists for walk through surveys. Both walk throughs and observations of the work rely on skills of trained observers with the fundamental difference that observational methods systematically sample (parts of) the work of individual workers, whereas walk throughs quickly survey the workers' exposure. In this paper systematic observation at the workplace is discussed, which is more than just looking about to obtain initial information on the job or data as well as exposures obtained by means of other methods of measurement. When workers are restricted to 
Table 1 The usefulness (in terms of accuracy and applicability) of measurement methods to assess the external exposure dimensions of level, duration, and frequency of variables regarding the working situation, the actual working method, and the triad of postures, movements, and exerted forces

\begin{tabular}{|c|c|c|c|c|}
\hline Exposure variable & Measurement method & Level & Duration & Frequency \\
\hline Working situation & $\begin{array}{l}\text { Expert judgements } \\
\text { Self reports } \\
\text { On site observation } \\
\text { Retrospective video observation } \\
\text { Direct measurements at work } \\
\text { Simulations in the laboratory }\end{array}$ & $\begin{array}{l}+ \\
+ \\
+ \\
-1+ \\
++ \\
--\end{array}$ & $\begin{array}{l}-/+ \\
-/+ \\
++ \\
+ \\
+ \\
--\end{array}$ & $\begin{array}{l}-/+ \\
-/+ \\
-/+ \\
+ \\
+ \\
--\end{array}$ \\
\hline Actual working method & $\begin{array}{l}\text { Expert judgements } \\
\text { Self reports } \\
\text { On site observation } \\
\text { Retrospective video observation } \\
\text { Direct measurements at work } \\
\text { Simulations in the laboratory }\end{array}$ & $\begin{array}{l}+ \\
+ \\
+ \\
+ \\
-1+ \\
++\end{array}$ & $\begin{array}{l}-/+ \\
-/+ \\
++ \\
++ \\
-/+ \\
+\end{array}$ & $\begin{array}{l}-/+ \\
-/+ \\
-/+ \\
++ \\
-/+ \\
+\end{array}$ \\
\hline Posture & $\begin{array}{l}\text { Expert judgements } \\
\text { Self reports } \\
\text { On site observation } \\
\text { Retrospective video observation } \\
\text { Direct measurements at work } \\
\text { Simulations in the laboratory }\end{array}$ & $\begin{array}{l}-1+ \\
- \\
+ \\
+ \\
+ \\
++\end{array}$ & $\begin{array}{l}-1+ \\
- \\
++ \\
++ \\
++ \\
+\end{array}$ & $\begin{array}{l}- \\
- \\
-1+ \\
++ \\
++ \\
+\end{array}$ \\
\hline Movement & $\begin{array}{l}\text { Expert judgements } \\
\text { Self reports } \\
\text { On site observation } \\
\text { Retrospective video observation } \\
\text { Direct measurements at work } \\
\text { Simulations in the laboratory }\end{array}$ & $\begin{array}{l}- \\
-- \\
- \\
-1+ \\
++ \\
++\end{array}$ & $\begin{array}{l}- \\
- \\
-1+ \\
+ \\
++ \\
+\end{array}$ & $\begin{array}{l}- \\
- \\
-1+ \\
++ \\
++ \\
+\end{array}$ \\
\hline Exerted force & $\begin{array}{l}\text { Expert judgements } \\
\text { Self reports } \\
\text { On site observation } \\
\text { Retrospective video observation } \\
\text { Direct measurements at work } \\
\text { Simulations in the laboratory }\end{array}$ & $\begin{array}{l}- \\
-1+ \\
- \\
-- \\
++ \\
++\end{array}$ & $\begin{array}{l}-/+ \\
-/+ \\
+ \\
+ \\
++ \\
+\end{array}$ & $\begin{array}{l}-/+ \\
-/+ \\
-/+ \\
+ \\
+ \\
+\end{array}$ \\
\hline
\end{tabular}

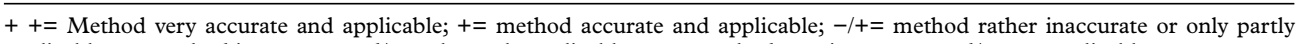
applicable; $-=$ method inaccurate and/or only partly applicable; $--=$ method very inaccurate and/or not applicable.

one workstation, their activities can be registered by video. Afterwards, the exposure can be observed from a television with the opportunity to use slow motion and to review the video tape. A disadvantage of this method is that perspective error might occur when workers rotate a lot from the optimal viewing angle, which is for trunk flexion, for instance, at right angles to the sagittal plane. ${ }^{14}$ Another obvious problem of video registration is that workers sometimes disappear from sight when moving around. This drawback is even worse for advanced optoelectronic systems that directly measure the change of position of body segments. Direct measurement instruments attached to the worker that record postures and movements include goniometers, inclinometers, and accelerometers. Furthermore, direct measurement tools vary from force gauges for assessment of exerted forces up to electromyographic registration instruments to measure muscle activity, and even a measuring rule to take the ergonomic dimensions of the workplace. However, sometimes it is impracticable to actually measure at the workplace or it is not possible to achieve the required accuracy and precision by measuring at the workplace. If this is the case, the working situation has to be simulated in the laboratory. Usually, subjective judgements or field observations initially provide information on the relevant aspects of the working situation, so that the simulations are a true to life rendering of the actual working method. Table 1 shows an evaluation of the usefulness of the different methods of measurement in ergonomic epidemiological studies. The evaluative marks (see caption of the table) were based on consensus among six ergonomic researchers, including ourselves. The usefulness of these methods was judged on accuracy as well as applicability. Other relevant factors - such as the aetiological significance of exposure measures or the cost effectiveness of measurement methods-were not considered in this systematic evaluation, but do play an important part in the planning of assessment of mechanical exposure.

\section{WORKING SITUATION}

A few exposure measures can be made independently of the worker. For instance, the ergonomic dimensions of the workplace can be assessed without the actual presence of the worker and the resulting exposure measures are purely external. Many exposure variables of the working situation can easily be assessed by experts, for instance by walk through. Epidemiologists can also make good use of more objective means like production figures, the number of daily transported packages, or description of the job and tasks to be performed. However, the resulting measures of individual exposure to work demands are crude, and it is rarely possible to distinguish the dimensions level, duration, and repetitiveness (frequency). Favourable exceptions are, for instance, the size and weight of objects to be handled or table height. When directly measured, the exposure level of these variables of the working situation can be estimated accurately and precisely, which is more difficult for the frequency and duration dimensions. 
ACTUAL WORKING METHOD

The actual working method partly depends on the individual worker, so that exposure variables cannot be assessed without concrete knowledge of the way that tasks are performed. For instance, when a task consists of the transportation of goods, is it done manually or by forklift truck? There is evidence that self reports such as diaries and questionnaires are able to distinguish differences in the actual working method when the occupational activities are classified dichotomously, ${ }^{15}{ }^{16}$ but less satisfactory results have been found when increased precision was strived for. ${ }^{15}{ }^{17}$ Furthermore, most questions on activities cover two exposure dimensions at once, usually either level and frequency or level and duration, which leaves the third dimension unanswered when only one question on the same activity is asked. Observational methods are generally suitable to accurately assess variables about the actual working method. However, to obtain data on the frequency of occupational activities real time observation is required (see observation of postures). Recently, an ambulatory monitoring method that provides information on whole body activities has been developed to measure the duration and frequency dimensions of exposure to walking, sitting, standing, and kneeling. ${ }^{18}$ Likewise, pedometers and posimeters validly assess the number of footsteps and the duration of sitting respectively. ${ }^{19}$

POSTURES

For the assessment of exposure to harmful working postures the whole range of measurement methods, from subjective judgements to direct measurements, has been applied in epidemiological studies. The scientific, practical, and financial pros and cons of the available methods have been already discussed in the scientific literature.$^{681320}$ In summary, several studies have led to the conclusion that self reported exposure data cannot validly replace observations or direct measurements in the assessment of the duration of exposure to harmful working postures during a specific period..$^{17}{ }^{21}$ Therefore, it is our opinion that epidemiologists should resist the temptation of using self reports such as questionnaires, diaries, or interviews to assess postural exposure at an individual level. Recently, the advantages and disadvantages of systematic observation have been discussed extensively. ${ }^{1322}$ In general, at the workplace a limited number of postural variables, each subdivided into two or more categories, can be registered reliably. Furthermore, trained observers are able to estimate body angles of subjects in a static posture to a high level of both accuracy and precision, ${ }^{142324}$ but validity proved to be unsatisfactory for very dynamic lifting tasks. ${ }^{25}$ Observing dynamic tasks at the workplace is an example of forcing quarts into pint pots, as movements have to be regarded as postures, whereas visual acuity rapidly deteriorates as the angular velocity exceeds $60^{\circ} \mathrm{s}^{-1} .^{26}$ Dynamic activities require either video observation or direct measurements, not only because serious information bias may occur in exposure data on working postures, but also because movements are rather different from postures from a biomechanical point of view. It is well known that internal exposure levelssuch as lumbar peak compressive forces-are much higher during angular acceleration of the trunk than those in a static situation. ${ }^{27}$ Most observational methods use time sampling to make a "snap shot" each 15 or 20 seconds, which means that the resulting exposure measures consider the relative frequency (duration dimension) of postural categories (level dimension). Insight into repetitiveness (frequency dimension) or temporal variation requires real time or simulated real time registration of working postures, which is only possible by video observation for most jobs. Finally, it has rightly been suggested that the different observation methods should be internationally standardised. ${ }^{13} 22$ We recommend categorisation of the different body segments in accordance with standards on working postures (ISO/CD 11226). The three categories for trunk flexion would then be: $<20^{\circ}, 20^{\circ}-60^{\circ}$, and $>60^{\circ}$.

MOVEMENTS

Strangely enough, in the scientific literature little attention has been paid to assessment of exposure to movements and exerted forces, although there are indications that posture is of about the same importance as risk factors related to movement ${ }^{28}$ and exerted force during manual handling of materials. ${ }^{28}{ }^{29}$ Some studies even indicated that for dynamic situations measures on motion-for example, angular velocity or acceleration-were more predictive than postural exposures for the risk of occupational disorders of the low back ${ }^{30}$ and wrist. ${ }^{31}{ }^{32}$ However, movement of body parts is very difficult to estimate on the face of it. Only by video observation in slow motion and by direct methods of measurement, either at work or in the laboratory, can one or more of the dimensions of exposure to movement be assessed accurately. Recently it was reported that the results obtained by video observation and direct measurement are highly comparable for accuracy and reliability. ${ }^{33}$

\section{EXERTED FORCES}

For assessment of exerted forces, expert judgements and observational methods rely heavily on the weight of lifted or lowered objects, which obviously gives only an indication of the level of the force actually exerted. In the case of carrying, the applied force can be estimated most accurately from the weight of the object. This is more difficult for pushing and pulling than for lifting, in particular for initial forces to get an object in motion. Perception of level and duration of force exerted significantly differed from the actual measured values. ${ }^{34}$ Furthermore, self reported levels of push and pull forces in simulated familiar tasks were inaccurate, but the subjects were able to correctly reproduce these forces. ${ }^{35}$ This finding might be useful in ergonomic studies. In general, however, direct methods of measurement are the only serious option to accurately assess exerted 
forces. Methods vary from simple force gauges to a complex three dimensional measuring frame for pushing and pulling. ${ }^{36}$ Measurements with simple force gauges can only result in peak and mean forces, whereas a three dimensional measuring frame enables calculations with the exerted force, which vary with time when workers pick up tools or push manual handling aids. For instance, the time integral of the external force would be an appropriate measure of exposure that includes the level and duration dimension. ${ }^{37}$

\section{Internal exposure of the musculoskeletal system}

In most publications biomechanical models are used to obtain the magnitude of internal exposure, which we extensively discuss. After that, we give attention to combinations of the magnitude (dimension level), with one or two of the other dimensions. Finally, the usefulness of internal exposure measures from electromyography and intra-abdominal pressure is considered.

BIOMECHANICAL MODELS

To obtain measures of internal exposure two fundamentally different types of models are used, a linked segment model and a distribution model. Firstly, from external exposure data (posture, movement, exerted force) and anthropometrical details, resulting net joint moments and forces can be calculated by linked segment models. In these models the human body is represented as a set of articulated links in a kinetic chain, the articulations corresponding to body joints. Intersegmental moments and forces are calculated either upward or downward, starting from ground reaction forces measured by a force plate or from external forces at the hands, respectively. Secondly, by a distribution model and possibly data considering muscle activity, the apportionment of the net moment and forces over the different muscles and passive structures can be estimated. However, it should be noted that the same net moment on-for instance, the shoulder-can be accompanied by largely different muscle activities due to the large number of possible motor unit solutions, both with and without coactivation in the antagonist muscles.

Biomechanical models, combinations of linked segment and distribution models, vary from two dimensional static models to three dimensional dynamic models that can be assisted by electromyography and data on intra-abdominal pressure. In field studies, it is difficult to obtain information on postures, movements, and exerted forces with the precision needed for input into more complex three dimensional dynamic biomechanical models. In particular acceleration and deceleration are hard to assess reliably for each segment of the body, to estimate the corresponding inertial forces. However, it should be noted that for a relatively simple model, like the widely used two dimensional static strength prediction model, ${ }^{38}$ not only five body segment angles have to be assessed, but also level and direction of the exerted forces. Moreover, some of these simple models also require anthropometrical information on segment lengths or volumes for the subjects under study to estimate the mass and location of the centre of mass for the different segments. By way of illustration, neither workers' self reports nor observations during work resulted in accurate estimates of peak exposure on the low back when using a quasidynamic two dimensional model. ${ }^{39}$ The main advantage of dynamic models is that the influence of jerky movements and accelerations of parts of the body can be measured, whereas for a three dimensional model the obvious improvement on a two dimensional approach is that non-symmetric tasks can also be evaluated. In general, the applicability of two dimensional static models is satisfactory, but there can be doubts about their accuracy. Three dimensional dynamic models yield the most accurate estimations of internal exposure, but are less easy to apply in epidemiological studies.

However, most biomechanical models used in ergonomic epidemiology estimate the net moment at the lumbosacral joint (L5-S1) as well as the compressive and shear forces at that position of the spine. The focus on the low back, although the most often affected part of the musculoskeletal system, is only partly justified as pain and discomfort in the neck, upper limbs, and lower limbs are also common. However, in particular the neck and shoulder joints cause difficulties with the distribution part of modelling. In fact, to our knowledge, only one three dimensional dynamic model for the shoulder exists, ${ }^{40}{ }^{41}$ but this model has been little used in occupational biomechanics as yet. In conclusion, it is recommended that advanced models for parts of the body other than the low back are used in ergonomic epidemiology more often than has been done to date.

The reader should note that in this paper only the level dimension of internal exposure has been covered so far, neither duration nor frequency has been included in the exposure measures resulting from biomechanical analysis. Epidemiology has this drawback, as the question of whether adverse health effects are caused by high peak exposures or by cumulative submaximal exposures is still unanswered. Jobs that impose less than $3.4 \mathrm{kN}$ of peak compressive force on the lumbar back are considered to be safe, ${ }^{42}$ but in vitro studies have shown that cyclic loading at submaximal compressive force levels may also cause damage to vertebral motion segments. However, there are some examples of studies that considered more than one internal exposure dimension. The level and duration dimension were combined to obtain a dose measure by calculating a cumulative internal load, ${ }^{43}$ or more precisely, an integral over time. ${ }^{27}{ }^{44}$ Magnusson et $a l^{45}$ gave insight into linked internal exposure data for the mean level and duration as well as for the peak level and frequency. They used the combination of peak compressive force and frequency in a model to predict damage to vertebral motion segments, assuming that failure due to fatigue is the underlying mechanism in 
cyclic compression. ${ }^{46} \mathrm{~A}$ recent analysis by Van Dieën and Toussaint ${ }^{47}$ included all three principal dimensions of internal exposure to predict the relative probability of damage to lumbar spine motion segments with two alternative simulation models. One of the models was based on the same mechanism of failure due to fatigue, ${ }^{46}$ whereas in the other the viscoelastic deformation was estimated to apply the maximum distortion energy criterion. ${ }^{48}$ The authors were able to evaluate varying levels (peak compressive forces due to different postures and loads), durations, and frequencies during a repetitive lifting task with both models, which led them to the conclusion that temporal aspects might have to be weighted logarithmically instead of linearly in epidemiological studies. Normally, the linear relation between duration of exposure and risk of damage is assumed when dose measures are calculated. Modelling approaches-such as the promising examples already mentioned-seem to be useful to ergonomic epidemiology and should be further elaborated on. In particular, the predictive validity of the different models for musculoskeletal health effects should be studied.

ELECTROMYOGRAPHY AND INTRA-ABDOMINAL PRESSURE

Electromyography (EMG) offers the possibility of obtaining a relative estimate of the force of contraction of a muscle. This information can be used for biomechanical models, provided the lever arms of the muscles are known, but it can in itself also be considered as internal exposure. Each of the three principal exposure dimensions can be obtained from EMG data, which was described with emphasis on the repetitiveness (frequency) dimension by Mathiassen and Winkel. ${ }^{49}$ The EMG signal is easily registered on the skin (surface EMG), for which the bipolar electrode technique is mostly used. The technique of EMG is a powerful tool in ergonomic epidemiology, ${ }^{50}$ but has its limitations. Important information bias can be introduced by cross talk, (activity of other muscles than the one under study) and by the influence of external electromagnetic fields. Furthermore, it should be stressed that change in muscle length and contraction velocity is related to the muscle force at constant activation. Therefore, EMG only reliably estimates muscle force after calibration (for each subject). When these conditions are fulfilled, EMG might be a useful method to evaluate occupational activities on the basis of required muscle forces as well as development of fatigue in the muscles. However, the validity of translations of EMG amplitude from the upper trapezius into exerted muscle force and moment was seriously questioned for tasks involving large or fast arm movements. ${ }^{51}$ Even when the task is not dynamic, only an approximation of the absolute force produced by individual muscles can be obtained as at present no method is available to determine the exact force contribution from different synergistically contracting muscles. Muscle fatigue is an acute response rather than an internal exposure measure, and because of that beyond the scope of this paper. The same goes for self reports on level of fatigue or discomfort.

Furthermore, measurements of intraabdominal pressure have been used for both biomechanical modelling and internal exposure assessments. Intra-abdominal pressure is thought to produce a trunk extensor moment, which would be reflected in diminished extensor muscle activity and decreased compressive force on the low back. Various strategies of modelling intra-abdominal pressure and its effects on low back loading have been used, ${ }^{52}$ but publications are still controversial. ${ }^{53}$ However, we think that it might be useful to use intra-abdominal pressure in biomechanical modelling, but it should definitely not be used as a separate internal exposure measure.

\section{Measurement strategy}

Not only the optimal combination of methods of measurement has to be chosen, but also the most efficient number of workers participating in the study relative to the number of repeated measurements for each of these workers. So far, guidelines for measurement strategies have mainly been focused on observation at the workplace of trunk postures ${ }^{54}$ although direct measurements of upper limb postures ${ }^{55}$ and other methods - such as surface EMG and intra-abdominal pressure-were also considered. $^{56}$ Burdorf $^{57}$ has introduced the importance of insight into the different sources of variance in exposure to non-neutral trunk postures in the field of ergonomic epidemiology. In his study the group status was the principal source of variance, which is a desirable feature in the comparison of occupational groups. In a subsequent study, however, the variability within workers was the most important source of variance for workers performing dynamic tasks in varying working situations, ${ }^{58}$ which implies that the measurement strategy should aim at more repeated measurements per worker or increased contrast in exposure to non-neutral trunk postures in the population under study. Exposure variability within the workers is a determinant of biased estimators of true exposure, which leads to nondifferential misclassification. Burdorf ${ }^{59}$ showed that this bias results in attenuation of the association with low back pain. It is clear that the same reasoning holds for other exposure and confounding variables, with the addition that overestimation of the relative risk may occur for one or more of these variables when they are correlated with mechanical exposure and more accurately measured than mechanical exposure. ${ }^{659}$ Thus, assessment of exposure and confounding variables require a well defined measurement strategy, for which estimates of the different sources of variance in exposure should be obtained before the main study. Furthermore, the choice for epidemiological analysis of individual means, group means, or estimates from alternative grouping strategies depends largely on the relative magnitude of the components of variance. ${ }^{60}$ When a grouped exposure assessment approach is chosen, the required sample size to obtain a valid 
estimate of the average exposure of the total group of workers is an important issue. A bootstrapping analysis showed that monitoring between 15 and 25 workers a group might be sufficient for exposure to trunk flexion. ${ }^{54}$ Finally, it is recommended that more attention be paid to the design of appropriate measurement strategies of mechanical exposures other than those related to trunk postures.

\section{Discussion}

Instruments are getting better all the time, for instance, a triaxial electrogoniometer to assess the three dimensional angular position, velocity, and acceleration characteristics can be used at the workplace. ${ }^{30}$ Furthermore, EMG instrumentation has become more easy to work with for both researchers and subjects. Thus, EMG assisted biomechanical models can be used to assess spinal compression during occupational activities provided that information is available on exerted external forces. Results from these models may help to explain, biomechanically, why epidemiological studies have identified certain risk factors for musculoskeletal disorders. It is also recommended that internal exposure measures resulting from EMG are more often related to health effects. In general, in future epidemiological studies, hypotheses should not only be formulated to examine whether relations exist between mechanical exposures and adverse health effects, but also to determine the relative importance of physical as well as social, organisational, and individual risk factors for the development and aggravation of the musculoskeletal complaints. Consequently, many different aspects of the working situation and the worker's capacity should be related to health effects, rather than solely a single exposure variable.

It has been argued before that biomechanical modelling requires precise and accurate estimates for many different variables, which has serious consequences for the design of epidemiological studies. By contrast with Wells et al, ${ }^{7}$ we think that data obtained through on site observation are generally too crude to use for biomechanical analysis to estimate the compressive and shear forces at the L5-S1 intervertebral disc as indices of internal exposure. This is even more the case for self reported postural data as diaries and questionnaires generally yield less accurate and precise estimates than observations. This was shown by De Looze et $a l,{ }^{25}$ who found that the ranges of possible spinal compressive forces are large for each postural category and these ranges overlap each other considerably. Consequently, video analysis by observation or more advanced, direct measurement techniques should be used in epidemiological field studies that eventually aim at internal exposure measures. However, when these methods are not applicable, for instance because of the dynamic nature of the job or interference with the job, a two staged approach is proposed. Firstly, methods that rely on self reports or observations give an impression of the working situation and corresponding actual working method. Secondly, the actual working method is simulated in a laboratory mock up by experienced workers. In the laboratory far more accurate and precise measurements can be made, for instance ground reaction forces assessed by a force platform, so that the simulated tasks can be biomechanically analysed properly. We agree, however, with the attempts of Wells et al to arrive at a common metric, in the case of spinal compressive and shear forces an estimate of internal exposure in Newtons. Moreover, integration of two or even three of the principal exposure dimensions into a single metric should be aimed at. For instance, in a recent study the subjective discomfort resulting from level and frequency combinations of both wrist posture and exerted force were assessed, although the duration was kept constant at one hour. ${ }^{61}$ Both dimensions of these two external exposure variables were successfully modelled into a single metric corresponding to discomfort. By the modelling approaches already discussed, combination of the principal dimensions of internal exposure seem to be promising. ${ }^{47}$

\section{Conclusions}

Six methods of measurement to assess external mechanical exposure in epidemiological studies were systematically evaluated for usefulness. Diaries and questionnaires offer the possibility to investigate many subjects at a reasonable cost, but most estimates of external exposure are imprecise and inaccurate. ${ }^{6}$ However, these self reports can give some insight into the occurrence of tasks and activities, and the approximate proportion of time spent on each of them. When a task based strategy is chosen, exposure profiles by occupational task should quantitatively be assessed at the workplace or in the laboratory. Observations of occupational activities can best be joined with data from video observation or direct methods of measurement-such as electrogoniometers or inclinometers on working postures and movements. Optoelectronic systems offer the possibility of assessing details of postures as well as movements of many body segments at once. Direct methods of measurement are needed to accurately assess exerted forces. When laboratory simulations are considered to be necessary, it should be taken into account that information on duration and frequency over the working day can only be estimated from additional data collected at work. Internal exposure assessments require direct measurements and possibly video observation to enable biomechanical modelling. When these methods are not applicable a two staged approach is proposed. Initial observed or self reported data on the working situation and actual working method should provide information to make measurements during laboratory simulations possible in the second stage. With respect to usefulness, the price that has to be paid for the increase in accuracy of exposure estimates obtained by three dimensional dynamic models is that these models are more difficult to apply when compared with a two dimensional approach. Most biomechanical models used in 
ergonomic epidemiology estimate compressive and shear forces at L5-S1, whereas insufficient light has been shed on the neck and shoulder. Furthermore, the focus on the level dimension has left duration and frequency of internal exposure aside. Recently, however, promising efforts were made with simulation models. Electromyography as well as intra-abdominal pressure measurements can be used for biomechanical models. Electromyography is also considered to be a useful method to directly assess internal exposure, for which each of the three principal exposure dimensions can be obtained.

We thank Marco JM Hoozemans, Judith I Kuiper, P Paul FM Kuijer, and Bart Visser for their important contributions to the table as well as the paper. Furthermore, the comments of Svend Erik Mathiassen, Alex Burdorf, and both anonymous reviewers are gratefully acknowledged.

1 Van Tulder MW, Koes BW, Bouter LM. A cost-of-illness study of back pain in The Netherlands. Pain 1995;62:23340.

2 Riihimäki H. Low-back pain, its origin and risk indicators. Scand $\mathcal{F}$ Work Environ Health 1991;17:81-90.

3 Armstrong TJ, Buckle PW, Fine LJ, et al. A conceptual model for work-related neck and upper-limb musculoskeletal disorders. Scand $\mathcal{F}$ Work Environ Health 1993;19 $73-84$

4 Bongers PM, De Winter CR, Kompier MAJ, et al. Psychosocial factors at work and musculoskeletal disease. Scand $\mathcal{F}$ Work Environ Health 1993;19:297-312.

5 Hagberg M. Exposure variables in ergonomic epidemiology. Am F Ind Med 1992;21:91-100.

6 Winkel J, Mathiassen SE. Assessment of physical work load in epidemiologic studies: concepts, issues and operational in epidemiologic studies: concepts, issues

7 Wells R, Norman P, Andrews D, et al. Assessment of physical work load in epidemiologic studies: common cal work load in epidemiologic studies: common measurement metrit

8 Burdorf A, Rossignol M, Fathallah FA, et al. Challenges in assessing risk factors in epidemiologic studies on back disorders. Am F Ind Med 1997;32:142-52.

9 Van Dijk FJH, Van Dormolen M, Kompier MAJ, et al. Herwaardering model belasting-belastbaarheid (Reappraisal of the model of workload and capacity). Tijdschrift Sociale Gezondheidszorg 1990;68:3-10.

10 Westgaard RH, Winkel J. Guidelines for occupational musculoskeletal load as a basis for intervention: a critical review. Applied Ergonomics 1996;27:79-88.

11 Hoozemans MJM, Van der Beek AJ, Frings-Dresen MHW, et al. Pushing and pulling in relation to musculoskeletal complaints: a review of risk factors. Ergonomics (in press).

12 Checkoway H, Pearce NE, Crawford-Brown DJ. Research methods in occupational epidemiology. Oxford: Oxford methods in occupation
University Press, 1989.

13 Kilbom $\AA$. Assessment of physical exposure in relation to work-related musculoskeletal disorders-what information
can be obtained from systematic observations. Scand $f$ can be obtained from systematic observations.
Work Environ Health 1994;20(special issue):30-45.

14 Douwes M, Dul J. Validity and reliability of estimating body angles by direct and indirect observations. In: Quéinnec Y, Daniellou F, eds. Designing for everyone. Proceedings of the $11^{\text {th }}$ Congress of the International Ergonomics Association; Fuly 1991. London: Taylor and Francis, 1991;885-7.

15 Wiktorin C, Karlqvist L, Winkel J, Stockholm MUSIC I study group. Validity of self-reported exposures to work postures and manual materials handling. Scand 7 Work Environ Health 1993;19:208-14.

16 Campbell L, Pannett B, Egger P, et al. Validity of a questionnaire for assessing occupational activities. Am f Ind Med 1997;31:422-6.

17 Van der Beek AJ, Braam ITJ, Douwes M, et al. The validity of a diary estimating tasks, activities, and postures of the trunk. Int Arch Occup Environ Health 1994;66:173-8.

18 Veltink PH, Bussmann HBJ, De Vries W, et al. Detection of static and dynamic activities using uniaxial accelerometers. IEEE Tran

19 Selin K, Winkel J, Stockholm MUSIC I study group. Evaluation of two instruments for recording sitting and standing postures and number of foot steps. Applied Ergonomics 1994;25:41-6.

20 Burdorf A. Exposure assessment of risk factors for disorders of the back in occupational epidemiology. Scand 7 Work Environ Health 1992;18:1-9.

21 Burdorf A, Laan J. Comparison of methods for the assessment of postural load on the back. Scand f Work Environ Health 1991;17:425-9.

22 Juul-Kristensen B, Fallentin N, Ekdahl C. Criteria for classification of posture in repetitive work by observation methods: a review. International fournal of Industrial Ergonomics 1997;19:397-411.
23 Van der Beek AJ, Van Gaalen LC, Frings-Dresen MHW. Working postures and activities of lorry drivers: a reliability study of on-site observation and recording on a pocket computer. Applied Ergonomics 1992;23:331-6.

24 Genaidy AM, Simmons RJ, Guo L, et al. Can visual perception be used to estimate body part angles? Ergonomics 1993;36:323-9.

25 De Looze MP, Toussaint HM, Ensink J, et al. The validity of visual observation to assess posture in a laboratorysimulated material handling task. Ergonomics 1994;37: 1335-43.

26 McCormick EJ, Sanders MS. Human factors in engineering and design, 5th ed. Singapore: McGraw-Hill, 1983.

27 Leskinen TPJ. Comparison of static and dynamic biomechanical models. Ergonomics 1985;28:286-91.

28 Burdorf A, Sorock G. Positive and negative evidence on risk factors for back disorders. Scand $\mathcal{f}$ Work Environ Health 1997;23:243-56.

29 Kuiper JI, Burdorf A, Verbeek JHAM, et al. Epidemiologic evidence on manual materials handling as risk factors for back disorders. A systematic review. International fournal of Industrial Ergonomics (in press).

30 Marras WS, Schoenmarklin R. Wrist motions in industry. Ergonomics 1993;36:341-51.

31 Marras WS, Lavender SA, Leurgans SE, et al. Biomechanical risk factors for occupationally related low back disorders. Ergonomics 1995;38:377-410.

32 Malchaire JB, Cock NA, Piette A, et al. Relationship between work constraints and the development of musculoskeletal disorders of the wrist: a prospective study. International fournal of Industrial Ergonomics 1997;19:47182.

33 Leinonen $\mathrm{T}, \mathrm{Ma} \mathrm{X}$. Comparison and contrast of methods for measuring movements. International fournal of Industrial Ergonomics 1996;18:229-37.

34 Kumar S. Perception of posture of short duration in the spatial and temporal domains. Applied Ergonomics 1993;24: spatial and

35 Wiktorin C, Selin K, Ekenvall L, et al. Evaluation of perceived and self-reported manual forces exerted in occupational manual materials handling. Applied Ergonomics 1996;27:231-9

36 Van der Beek AJ, Hoozemans MJM, Frings-Dresen MHW. Exposure assessment of pushing and pulling at the workplace. Proceedings of the Symposium: Risk Assessment for Musculoskeletal Disorders. Nordic Satellite Symposium under the auspices of ICOH '96. Copenhagen: National Institute of Occupational Health, 1996:53-4.

37 Van der Beek AJ, Hoozemans MJM, Frings-Dresen MHW, et al. Assessment of exposure to pushing and pulling in epidemiological field studies: an overview of methods, exposure measures and measurement strategies. International fournal of Industrial Ergonomics (in press).

38 Chaffin DB, Anderson GBJ. Occupational biomechanics. 2nd Cd. New York: John Wiley, 1991.
edin DB, Anderson GBJ. Occupat

39 Andrews D, Norman P, Wells R, et al. The accuracy of selfreport and trained observer methods for obtaining estimates of peak load information during industrial work. International fournal of Industrial Ergonomics 1997;19:44555.

40 Van der Helm FCT. A finite element musculoskeletal model of the shoulder mechanism. F Biomech 1994;27:551-69.

41 Van der Helm FCT. Analysis of the kinematic and dynamic behavior of the shoulder mechanism. F Biomech 1994;27: $527-50$

42 Waters TR, Putz-Anderson V, Garg A, et al. Revised NIOSH equation for the design and evaluation of manual lifting tasks. Ergonomics 1993;36:749-76.

43 Kumar S. Cumulative load as a risk factor for back pain. Spine 1990;15:1311-6.

44 De Looze MP, Visser B, Houting I, et al. Weight and frequency effect on spinal loading in a bricklaying task. $\mathcal{F}$ Biomech 1996;29:1425-33.

45 Magnusson M, Granqvist M, Jonson R, et al. The loads on the lumbar spine during work at an assembly line. The risks for fatigue injuries of vertebral bodies. Spine 1990;15:7749.

46 Hansson TH, Keller TS, Spengler DM. Mechanical behavior of the human lumbar spine. II. Fatigue strength during dynamic compressive loading. F Orthop Res 1987;5:479-87.

47 Van Dieën JH, Toussaint HM. Evaluation of spinal damage due to sustained cyclic compression loading. Human 997;39:469-80.

48 Van Dieën JH, Toussaint HM. Application of the maximum energy criterion to describe the strength of the motion segment under axial compression. Spine 1995;20:518-25.

49 Mathiassen SE, Winkel J. Assessment of repetitive work. Proceedings of the 2nd International Scientific Conference on Prevention of Work-related Musculoskeletal Disorders PREMUS 95. Montréal: Institut de recherche en santé et en sécurité du travail du Québec, 1995:232-4.

50 Aarås A, Ro O. Electromyography (EMG): methodology and application in occupational health. International fournal of Industrial Ergonomics 1997;20:207-14.

51 Mathiassen SE, Winkel J, Hägg GM. Normalization of surface EMG amplitude from the upper trapezius muscle in ergonomic studies: a review. fournal of Electromyography and Kinesiology 1995;5:197-226.

52 McGill SM, Norman RW. Reassessment of the role of intraabdominal pressure in spinal compression. Ergonomics 1987;30:1565-88.

53 Nachemson AL, Anderson GBJ, Schultz AB. Valsalva maneuver biomechanics. Effects on lumbar trunk loads of elevated intra-abdominal pressure. Spine 1986;11:476-9. 
54 Burdorf A, Van Riel M. Design of strategies to assess lumbar posture during work. International fournal of Industrial Ergonomics 1996;18:239-49.

55 Ortiz DJ, Marcus M, Gerr F, et al. Measurement of variability in upper extremity posture among VDT users. Applied Ergonomics 1997;28:139-43.

56 Heinrich I, Otun EO, Anderson JAD. Reproducibility of surface electromyogram and intra-abdominal pressure for use in ambulatory monitoring. Ergonomics 1988;31:182135.

57 Burdorf A. Sources of variance in exposure to postural load on the back in occupational groups. Scand $\mathcal{F}$ Work Environ Health 1992;18:361-7.
58 Van der Beek AJ, Kuiper JI, Dawson M, et al. Sources of variance in exposure to nonneutral trunk postures observed in varying working situations. Scand $\mathcal{f}$ Work Environ Health 1995;21:215-22.

59 Burdorf A. Bias in risk estimates arising from variability of exposure to postural load on the back in occupational groups. Scand F Work Environ Health 1993;19:50-4.

60 Seixas NS, Sheppard L. Maximizing accuracy and precision using individual and grouped exposure assessments. Scand $\mathcal{f}$ Work Environ Health 1996;22:94-101.

61 Lin ML, Radwin RG. A single metric for quantifying biomechanical stress in repetitive motions and exertions. Ergonomics 1997;40:543-58.

\section{Vancouver style}

All manuscripts submitted to Occup Environ $M e d$ should conform to the uniform requirements for manuscripts submitted to biomedical journals (known as the Vancouver style.)

Occup Environ Med, together with many other international biomedical journals, has agreed to accept articles prepared in accordance with the Vancouver style. The style (described in full in the $\mathcal{F} A M A[1]$ ) is intended to standardise requirements for authors, and is the same as in this issue.

References should be numbered consecutively in the order in which they are first mentioned in the text by Arabic numerals on the line in square brackets on each occasion the reference is cited (Manson[1] confirmed other reports[2][3][4][5]). In future references to papers submitted to Occup Environ Med should include: the names of all authors if there are three or less or, if there are more, the first three followed by et al; the title of journal articles or book chapters; the titles of journals abbreviated according to the style of Index Medicus; and the first and final page numbers of the article or chapter. Titles not in Index Medicus should be given in full.

Examples of common forms of references are:

1 International Committee of Medical Journal Editors. Uniform requirements for manuscripts submitted to biomed journals. $¥ A M A$ 1993;269:2282-6.

2 Soter NA, Wasserman SI, Austen KF. Cold urticaria: release into the circulation of histmaine and eosinophil chemotactic factor of anaphylaxis during cold challenge. N Engl f Med 1976;294:687-90.

3 Weinstein L, Swartz MN. Pathogenic properties of invading micro-organisms. In: Sodeman WA Jr, Sodeman WA, eds. Pathologic physiology, mechanisms of disease. Philadelphia: W B Saunders, 1974:457-72. 